\title{
Applying quality improvement principles to improve accident and emergency department overcrowding and flow in Rwanda: a case study
}

\author{
Jean Claude Byiringiro ${ }^{1}$, Rex Wong ${ }^{* 2}$, Caroline Davis ${ }^{2}$, Jeffery Williams ${ }^{3}$, Joseph Becker ${ }^{4}$, Joseph Novik ${ }^{5}$, Christine \\ Uwineza $^{1}$, Chance Delphine Mukakamali ${ }^{1}$, Theobald Hategekimana ${ }^{1}$, Martin Nyundo $^{1}$ \\ ${ }^{1}$ CHUK, Rwanda \\ ${ }^{2}$ Yale University Global Health Leadership Institute, United States \\ ${ }^{3}$ University of Illinois-Chicago, United States \\ ${ }^{4}$ Columbia University, United States \\ ${ }^{5}$ Brown University, United States
}

Received: April 25, 2015

Accepted: June 23, 2015

Online Published: July 7, 2015

DOI: $10.5430 /$ jha.v4n5p47

URL: http://dx.doi.org/10.5430/jha.v4n5p47

\begin{abstract}
Few case studies exist related to hospital accident and emergency department (A\&E) quality improvement efforts in lowerresourced settings. We sought to report the impact of quality improvement principles applied to A\&E overcrowding and flow in the largest referral and teaching hospital in Rwanda. A pre- and post-intervention study was conducted. A linked set of strategies included reallocating room space based on patient/visitor demand and flow, redirecting traffic, establishing a patient triage system and installing white boards to facilitate communication. Two months post-implementation, the average number of patients boarding in the A\&E hallways significantly decreased from 28 (pre-intervention) to zero (post-intervention), $p<.001$. Foot traffic per dayshift hour significantly decreased from 221 people to 160 people $(28 \%, p<.001)$, and non-A\&E related foot traffic decreased from $81.4 \%$ to $36.3 \%$ (45\% decrease, $p<.001$ ). One hundred percent of the A\&E patients have been formally triaged since the implementation of the newly established triage system. Our project used quality improvement principles to reduce the number of patients boarding in the hallways and to decrease unnecessary foot traffic in the A\&E department with little investment from the hospital. Key success factors included a collaborative multidisciplinary project team, strong internal champions, data-driven analysis, evidence-based interventions, senior leadership support, and rapid application of initial implementation learnings. Results to date show the application of quality improvement principles can help hospitals in resource-limited settings improve quality of care at relatively low cost.
\end{abstract}

Key Words: Low resource setting, Hospital, Accident and emergency department, Patient flow, Quality improvement, Overcrowding

\section{INTRODUCTION}

Hospitals and other health care organizations worldwide have increasingly sought to improve patient care quality and opera- tional efficiency. ${ }^{[1-5]}$ Quality improvement, the management science of continuous improvement in work processes, has become an expected competency in health care organizations

*Correspondence: Rex Wong; Email: rex.wong@yale.edu; Address: Yale University Global Health Leadership Institute, United States. 
and forms the foundation for institutional accreditation. ${ }^{[6-8]}$ Health care quality improvement efforts draw from a variety of approaches (e.g. TQM, Six Sigma, Lean), yet all share some common principles: understanding process and systems; process measurement and standardization; capacity management (demand, supply, flow); customer focus; and staff engagement. ${ }^{[9]}$

Despite a vast body of literature assessing the impact of health care quality improvement efforts in the United States and in Europe, ${ }^{[3,4,10-14]}$ fewer studies have evaluated hospitalbased quality improvement efforts in low-income countries, particularly in sub-Saharan Africa. ${ }^{[15]}$ Similarly, while ample studies have examined the issue of emergency department overcrowding and flow in the US and Europe, less has been published from resource-challenged regions. ${ }^{[16-20]}$

Hospital quality improvement efforts in lower-resourced settings are increasingly common ${ }^{[21]}$ and several studies offer specific examples of how these efforts have proved beneficial to the provision of basic care processes, ${ }^{[22]}$ cardiac catheterization lab flow, ${ }^{[23]}$ overall hospital performance, ${ }^{[24]}$ and medical records. ${ }^{[25]}$ Still, few published studies exist related specifically to emergency department quality improvement efforts in low-income countries.

Accordingly, we sought to examine the impact of quality improvement principles applied to emergency department overcrowding and flow in the largest referral and teaching hospital in Rwanda. This effort was part of Rwanda's Human Resources for Health (HRH) program, a national initiative to build the hospital management, physician, and nursing workforce sponsored by USAID and directed by the Rwandan Ministry of Health. ${ }^{[26]}$ Using a peer-mentoring model, HRH partners United States and Rwandese physicians, nurses and hospital managers to build capacity. The Accident and Emergency department (A\&E) problems of overcrowding and flow provided an ideal opportunity to leverage the HRH resources and approach toward improving quality while building leadership and management capacity. Findings from this study may be useful for other health care management capacity-building efforts or quality improvement initiatives in resource-challenged settings.

\section{Methods}

\subsection{Setting}

We conducted the study in the Rwanda's largest teaching hospital, which serves as the primary referral hospital for the entire country of almost 12 million people. Rwanda is a small, land-locked country in sub-Saharan Africa. Its health system was completely re-built after the 1994 genocide, and now includes thousands of health posts and centers feeding into a network of 44 district and referral hospitals. Rwanda also offers universal health insurance to its citizens.

The study site hospital has 471 beds and an occupancy rate of $72 \%$. During the fiscal year ending July 2013, the hospital's A\&E department served 30,243 patients. Prior to the study, many A\&E patients were boarding in hallways. Nurses responsible for hallway patients had little ability to monitor patient status as patients were scattered throughout the busy corridors. There were also many people passing through the department on non-A\&E-related business, adding to the crowding.

Although the hallways were congested due to overflow patient beds and traffic, six rooms within the department were underutilized, including one large open area near the ambulance bay. An alcove next to a busy patient, caregiver and staff area was used for dead bodies awaiting transit to the morgue. There was no designated area to triage patients or isolate contagious patients. The compartmentalized layout of the A\&E rooms did not facilitate communication, and staff had no easy and consistent way to know department census and capacity.

\subsection{Study design and sample}

We conducted a pre- and post-intervention study to examine the impact of quality improvement principles on crowding and flow in a Rwanda referral hospital emergency department. Pre-intervention baseline data were collected for one month in December 2012 and repeated in June 2013, two months after implementation. The pre- and post-intervention samples involved daily counts of all patients boarding in the emergency department hallways and hourly counts of foot traffic during dayshift hours, excluding on-duty A\&E staff.

\subsection{Intervention}

A linked set of strategies was implemented to reduce patient crowding and improve flow. These included reallocating room space based on patient/visitor demand and flow and redirecting traffic based on patient/visitor need and work flow. These changes were facilitated by the establishment of a patient triage system. Implementation began in April 2013 and was continued to monitor over the course of several months.

The primary project team was the A\&E Steering Committee, led by the physician head of department. The group included department physician and nursing leadership and staff as well as select HRH faculty, a mix of experienced emergency medicine physicians, nurses and hospital managers.

The A\&E steering committee, in collaboration with frontline staff, identified project goals; collected and analyzed baseline 
data; developed and implemented recommended changes; and evaluated and monitored results. Related to the effort to address overcrowding and patient flow, this group also established a formal patient triage tool and process.

The first step was to re-route non-A\&E traffic to outside the department. In March 2013, a new cashier office space was created in the back of an unused sluice area, located just outside the entrance to the A\&E department. The preparation of the sluice room was completed in March for the relocation in April. By moving the cashier outside the department, cashierrelated traffic was prevented from moving through A\&E and two rooms were availed for patient care. Visitors going to nearby inpatient areas were also re-routed to minimize unnecessary traffic in the A\&E. Dead bodies were delivered directly to the morgue.

Space reallocation had the most significant impact on overcrowding. In April 2013, hallway patients and their family caregivers were relocated to what was the previous cashier waiting area. Nurses caring for these patients were now able to see all of their patients in one room versus scattered down a long and crowded hallway. Clear hallways also improved infection control, facilitated egress and reduced overall department chaos. For infection prevention and control concerns, a two-bed isolation room was created in the former cashier's office. Understanding the need for office space for clinicians, a previously underutilized room was converted into an interdisciplinary office and conference room.

A formalized triage bay and process were established in April 2013. The triage location was strategically placed to ensure that nurses could have constant line-of-sight of the ambulance entrance, the triage bay and the non-urgent patient waiting area. The steering committee selected and modified the South African Triage Scale (SATS) as its triage tool. ${ }^{[27]}$ Staff were trained on the triage tool and the associated triage process during March and April 2013. A resuscitation team was formed, trained and assigned to support the new triage process. Staffing patterns and schedules were adjusted accordingly.

A simple visual management technique was used to communicate department status and capacity. A large white board was mounted in the triage bay area to enhance intra-and interdepartmental communication. Important information related to department capacity was listed, including patients pending triage, room census levels, staffing by room, assigned resuscitation team members and key phone numbers. This simple approach provided staff with a real-time understanding of patient demand relative to department resources (staff and room capacity).

Published by Sciedu Press

\subsection{Data and measures}

Our primary outcome measures were: 1) the number of patients boarding in hallways per day; and 2) the number of people walking through the A\&E department (foot traffic) throughout different dayshift hours. The foot traffic data were further divided into A\&E-related activities (i.e. staff accompanying patients and on-duty staff walking through $\mathrm{A} \& \mathrm{E}$ ) and non-A\&E-related activities (i.e. visitors walking to cashier, visitors for inpatient units).

\subsection{Data analysis}

Independent sample $t$-tests were used to compare the preand post-intervention average number of hallway patients as well as the average number of people walking through A\&E (foot traffic) per dayshift hour. A chi-square test was used to compare the pre- and post-intervention percentages of A\&E and non-A\&E-related traffic. All data analysis was completed using SPSS v.17 statistical software at a significance level of $p=.05$.

\section{RESULTS}

Between September and December 2012, we conducted a baseline assessment. Beginning in September, we observed department patient flow for several days, collecting and analyzing data using department patient registers and direct observation. We analyzed incoming patient volume by day of week, calculated average department census by room and estimated patient length of stay by room. We mapped the department layout, functions and patient flow and assessed over-and underutilized space. In December, we quantified the number of patients boarding in hallways and department traffic by purpose, direction and volume.

In June 2013, two months post-implementation, the average number of patients boarding in the A\&E hallways significantly decreased from 28 (pre-intervention) to zero (post-intervention), $p<.001$. This result has sustained despite a $6 \%$ increase in A\&E volume during the corresponding period. Foot traffic per dayshift hour also significantly decreased from 221 people to 160 people $(28 \%, p<.001)$. The chi-square test also indicated a sizeable decrease in nonA\&E related foot traffic from $81.4 \%$ to $36.3 \%$ (45\% decrease, $p<.001)$. It is also worth noting that $100 \%$ of the A\&E patients have been formally triaged using the newly established triage system since late April 2013. Results are summarized in Table 1.

\section{Discussion}

Our project significantly reduced the number of patients boarding in the hallways and reduced unnecessary foot traffic in the A\&E department. The seven-month implemen- 
tation preparation included assessment, planning, training and monitoring. The project cost approximately 1,000 USD. Our project showed a well-designed project with data-driven implementation can successfully reduce overcrowding and improve patient flow with little investment from the hospital.

The project leveraged many quality improvement principles to address emergency department overcrowding and flow, a shared concern of patients, families and staff. A multidis- ciplinary team, including line staff, was used to define and measure the problem, devise interventions and implement change. Strong internal champions (physician and nursing department leadership) took real ownership of the project. Direct observation and measurement of workflow followed by data-driven analysis were used to understand demand, supply and flow as well as to define current state, root causes and interventions.

Table 1. Pre- and post-intervention measures of crowding

\begin{tabular}{lllll}
\hline Measures of Crowding & Pre-intervention & Post-intervention & Decrease & $p$-value \\
\hline No. of hallway patients & 28 & 0 & $100 \%$ & $<.001^{* *}$ \\
Foot traffic per hour & 221 & 160 & $28 \%$ & $<.001^{* *}$ \\
Non-A\&E-related traffic & $180(81.4 \%)$ & $102(36.3 \%)$ & $45.1 \%$ & $<.001^{* *}$ \\
A\&E-related traffic & $41(18.6 \%)$ & $58(63.8 \%)$ & Reference & Reference \\
\hline
\end{tabular}

Statistically significant at $p=.05$

Senior leadership approval was solicited and obtained in order to assure top-level institutional support for the changes. Detailed implementation planning was conducted, allowing for proper sequencing of changes and adequate training and trouble-shooting. In some cases, like the establishment of the isolation room, this meant delay of implementation until proper staffing levels or other critical enablers could be assured. In other cases, like the handling of the dead bodies, the original recommended approach was not feasible and had to be modified. Initial implementation learnings were identified and applied immediately, resulting in some rapid-cycle modifications to process and tools. For example, during the triage system set up, the team decided to use a whistle to alert the resuscitation team to any critical patient. However, staff informed us that a whistle is associated with the Rwandan genocide and is therefore culturally inappropriate. We immediately switched to a megaphone.

An existing department steering committee was leveraged as the forum for addressing the overcrowding problem and building leadership and management capacity, perhaps one of the most important aspects of this project. The project taught the steering committee how to apply quality improvement principles to solve problems, and as of the writing of this paper, the group continues to meet weekly to apply these principles to other departmental concerns such as linen management and nursing documentation.

The cost of the interventions was minimal, which was critical to the project's feasibility and ultimate success. Creating a cashier's office in the back of an unused sluice space and availing internet access at the new triage desk cost approximately $\$ 1,000$ US dollars. All needed furniture, equipment and supplies were sourced within the department or hospital at no additional cost.

Our findings should be interpreted in light of several limitations. First, our study was limited to a single organization. Results may differ in other settings, particularly as the impact of quality improvement efforts is highly contextdependent. ${ }^{[13]}$ Second, we could not assess sustainability and further follow-up is warranted, although the implemented changes have remained in place and the results persist as of the writing of this paper. Third, this study did not include measuring any outcome impact on the quality of service. Our study in improving the patient flow, however, was the first quality improvement effort in the A\&E department. Since then, some other quality improvement initiatives were conducted in the A\&E department to assess some outcomes as a result of this study; including improving A\&E staff compliance to the triage process, increasing the completeness and accuracy of the triage process through audits, and reducing door-to-triage and door-to-service times. These quality improvement efforts have yet to produce outcome data but such data will be available as the efforts are further along. Our effort first focused on management improvement; further studies should examine clinical endpoints. Fourth, we recognize the lack of a formal comparison group and use of historical comparisons is a weakness of the study; however, improvements made at this hospital were not seen at peer hospitals over the same time period. Limited resources as well as practical and ethical concerns, as may be expected in a low-income setting, prohibited us from establishing a formal comparison group.

This project demonstrates that quality improvement principles can help address emergency department overcrowding in a resource-challenged setting. By focusing on process 
and systems; capacity and work flow; the patient and visitor experience; and staff engagement, overcrowding has been reduced considerably and departmental flow enhanced. Results to date show that the application of quality improvement principles can help hospitals in resource-limited settings improve quality of care at a relatively low fiscal cost. Although the fiscal cost of the project was modest, the substantial amount of time and effort were spent in assessment, training, im-

\section{REFERENCES}

[1] Cohen AB, Restuccia JD, Shwartz M, et al. A survey of hospital quality improvement activities. Med Care Res Rev. 2008 Oct; 65(5): 571-95. PMid: 18511811. http://dx.doi.org/10.1177/10775 58708318285

[2] Restuccia JD, Mohr D, Meterko M, et al. The Association of Hospital Characteristics and Quality Improvement Activities in Inpatient Medical Services. J Gen Intern Med. 2014 Jan 15 [Epub ahead of print]. PMid: 24424776.

[3] DelliFraine JL, Langabeer JR, Nembhard IM. Assessing the evidence of Six Sigma and Lean in the health care industry. Qual Manag Health Care. 2010 Jul-Sep; 19(3): 211-25. PMid: 20588140. http://dx.doi.org/10.1097/QMH.0b013e3181eb140e

[4] Mazzocato P, Savage C, Brommels M, et al. Lean thinking in healthcare: a realist review of the literature. Qual Saf Health Care. 2010 Oct; 19(5): 376-82. PMid: 20724397. http://dx.doi.org/10. 1136/qshc. 2009.037986

[5] Walshe K. Pseudoinnovation: the development and spread of healthcare quality improvement methodologies. Int J Qual Health Care. 2009 Jun; 21(3): 153-9. PMid: 19383716. http://dx.doi.org/1 $0.1093 /$ intqhc/mzp012

[6] Joint Commission International. Available from: www. jointcommi ssioninternational . org [Accessed 24 February 2014].

[7] Council for Health Service Accreditation of Southern Africa. Available from: http://www. cohsasa.co.za/ [Accessed 24 February 2014].

[8] International Organization for Standards. Available from: www . iso . org [Accessed 24 February 2014].

[9] Boaden R, Harvey G, Moxham C, et al. Quality Improvement: Theory and Practice in Healthcare. National Library for Health, NHS Institute for Innovation and Improvement. 2008.

[10] Glasgow JM, Scott-Caziewell JR, Kaboli PJ. Guiding inpatient quality improvement: a systematic review of Lean and Six Sigma. Jt Comm J Qual Patient Saf. 2010 Dec; 36(12): 533-40. PMid: 21222355

[11] Andersen H, Røvik KA, Ingebrigtsen T. Lean thinking in hospitals: is there a cure for the absence of evidence? A systematic review of reviews. BMJ Open. 2014 Jan 15; 4(1): e003873. PMid: 24435890. http://dx.doi.org/10.1136/bmjopen-2013-003873

[12] DelliFraine JL, Wang Z, McCaughey D, et al. The use of six sigma in health care management: are we using it to its full potential? Qual Manag Health Care. 2013 Jul-Sep; 22(3): 210-23. PMid: 23807133. http://dx.doi.org/10.1097/QMH.0b013e31829a838e

[13] Kaplan HC, Brady PW, Dritz MC, et al. The influence of context on quality improvement success in health care: a systematic review of the literature. Milbank Q. 2010 Dec; 88(4): 500-59. PMid: 21166868. http://dx.doi.org/10.1111/j.1468-0009.2010.00611.x

[14] Poksinska B. The current state of Lean implementation in health care: literature review. Qual Manag Health Care. 2010 Oct-Dec; 19(4): 319-29. PMid: 20924253.

Published by Sciedu Press plementing change and building leadership capacity of the department and should be recognized.

\section{ACKNOWLEDGEMENTS}

The authors would like to thank the Rwanda Ministry of Health and its Human Resources for Health program. In addition, the project would not have been possible (nor the results sustained) without the hard work and commitment of the Accident \& Emergency department staff.

[15] Liu C, Babigumira J, Chiunda A, et al. Finding the best examples of healthcare quality improvement in Sub-Saharan Africa. Qual Saf Health Care. 2010 Oct; 19(5): 416-9. PMid: 20977994. http://dx.doi.org/10.1136/qshc. 2008.028548

[16] Institute of Medicine. Hospital-Based Emergency Care: At The Breaking Point. Washington, DC; 2006.

[17] Hoot NR, Aronsky D. Systematic review of emergency department crowding: causes, effects, and solutions. Ann Emerg Med. 2008 Aug; 52(2): 126-36. PMid: 18433933. http://dx.doi.org/10.1016 /j.annemergmed.2008.03.014

[18] Higginson I. Emergency department crowding. Emerg Med J. 2012 Jun; 29(6): 437-43. PMid: 22223713. http://dx . doi .org/10.11 36/emermed-2011-200532

[19] Boyle A, Beniuk K, Higginson I, et al. Emergency department crowding: time for interventions and policy evaluations. Emerg Med Int. 2012; 2012: 838610. PMid: 22454772. http://dx.doi.org/10. $1155 / 2012 / 838610$

[20] Pines JM, Hilton JA, Weber EJ, et al. International perspectives on emergency department crowding. Acad Emerg Med. 2011 Dec; 18(12): 1358-70. PMid: 22168200. http://dx.doi.org/10.11 $11 / j .1553-2712.2011 .01235 . x$

[21] Choo S, Papandria D, Goldstein SD, et al. Quality improvement activities for surgical services at district hospitals in developing countries and perceived barriers to quality improvement: findings from Ghana and the scientific literature. World J Surg. 2013 Nov; 37(11): 2512-9. PMid: 23897444. http://dx.doi.org/10.1007/s0026 8-013-2169-4

[22] Kotagal M, Lee P, Habiyakare C, et al. Improving quality in resource poor settings: observational study from rural Rwanda. BMJ. 2009 Oct 30; 339: b3488. PMid: 19880528. http://dx.doi.org/10. $1136 / \mathrm{bmj}$. b3488

[23] Wong R, Hathi S, Linnander EL, et al. Building hospital management capacity to improve patient flow for cardiac catheterization at a cardiovascular hospital in Egypt. Jt Comm J Qual Patient Saf. 2012 Apr; 38(4): 147-53. PMid: 22533126.

[24] Bradley E, Hartwig KA, Rowe LA, et al. Hospital quality improvement in Ethiopia: a partnership-mentoring model. Int J Qual Health Care. 2008 Dec; 20(6): 392-9. PMid: 18784268. http: //dx.doi.org/10.1093/intqhc/mzn042

[25] Wong R, Bradley EH. Developing patient registration and medical records management system in Ethiopia. Int J Qual Health Care. 2009 Aug; 21(4): 253-8. PMid: 19574294. http://dx.doi.org/10.10 93/intqhc/mzp026

[26] Binagwaho A, Kyamanywa P, Farmer PE, et al. The human resources for health program in Rwanda-new partnership. N Engl J Med. 2013 Nov 21; 369(21): 2054-9. PMid: 24256385. http: //dx.doi.org/10.1056/NEJMsr1302176

[27] Emergency Medicine Society of South Africa website on 23 February 2014. Available from: http://emssa.org.za/sats/ 